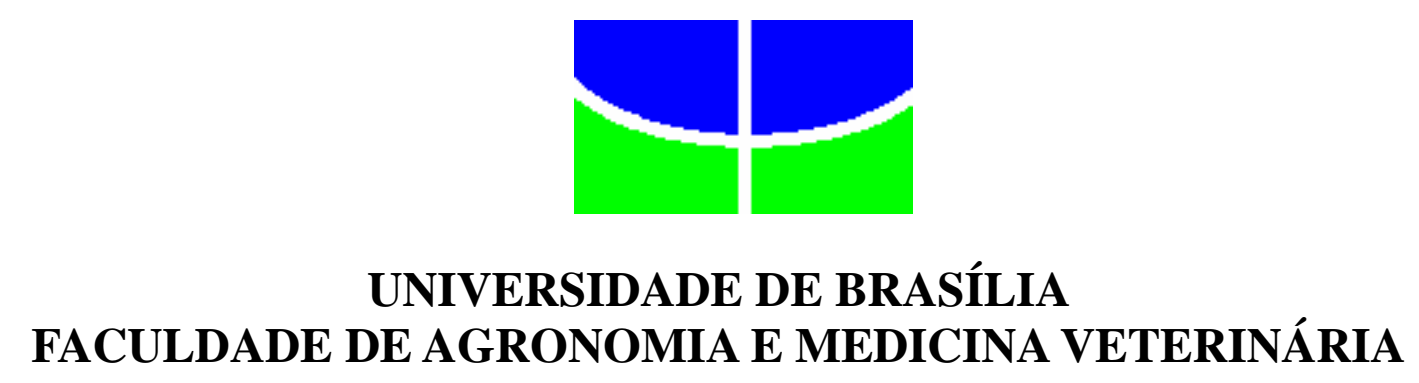

INDICADORES HEMATOLÓGICOS E BIOQUÍMICOS DO ESTRESSE EM TILÁPIAS (Oreochromis niloticus) SUPLEMENTADAS COM RACTOPAMINA

ANA PAULA PEREIRA MUNDIM

DISSERTAÇÃO DE MESTRADO EM CIENCIAS ANIMAIS 


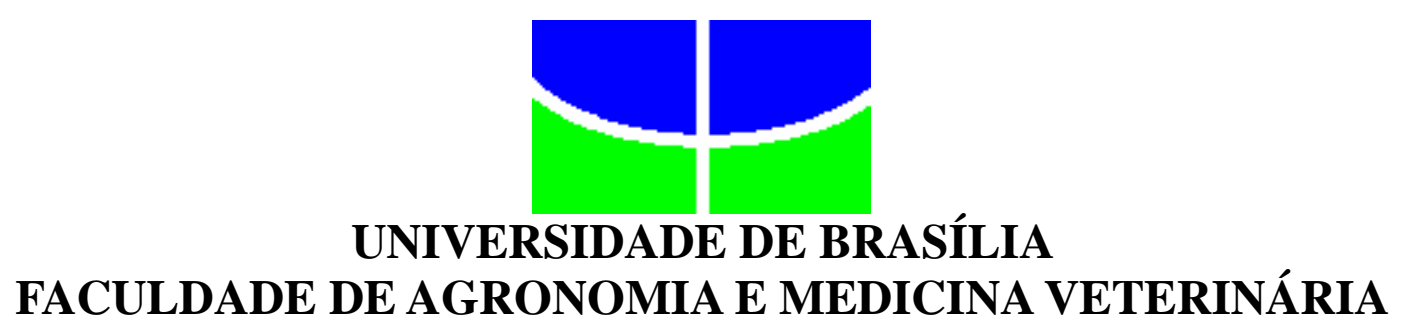

INDICADORES HEMATOLÓGICOS E BIOQUÍMICOS DO ESTRESSE EM TILÁPIAS (Oreochromis niloticus) SUPLEMENTADAS COM RACTOPAMINA

\author{
ALUNO: ANA PAULA PEREIRA MUNDIM
}

ORIENTADOR: PROF. DR. FRANCISCO ERNESTO MORENO BERNAL

DISSERTAÇÃO DE MESTRADO EM CIÊNCIAS ANIMAIS

PUBLICAÇÃO: 144/2015

BRASÍLIA-DF

DEZEMBRO DE 2015 
Ficha catalográfica elaborada automaticamente, com os dados fornecidos pelo(a) autor(a)

Mundim, Ana Paula Pereira

Indicadores hematológicos e bioquímicos do estresse

M965 i em tilápias (Oreochromis Niloticus) suplementadas com ractopamina / Ana Paula Pereira Mundim; orientador Francisco Ernesto Moreno Bernal. -Brasília, 2015.

$34 \mathrm{p}$.

Dissertação (Mestrado - Mestrado em Ciência Animal) -- Universidade de Brasília, 2015.

1. Piscicultura,. 2. Tilápia do Nilo. 3. bem estar animal. 4. Beta-adrenérgico. I. Moreno Bernal, Francisco Ernesto, orient. II. Título. 


\title{
INDICADORES HEMATOLÓGICOS E BIOQUIIMICOS DO ESTRESSE EM TILÁPIAS (Oreochromis niloticus) SUPLEMENTADAS COM RACTOPAMINA
}

\author{
ANA PAULA PEREIRA MUNDIM
}

DISSERTAÇÃO DE MESTRADO SUBMETIDA AO PROGRAMA DE PÓS-GRADUAÇÃO EM CIÊNCIAS ANIMAIS, COMO PARTE DOS REQUISITOS NECESSÁRIOS À OBTENÇÃO DO GRAU DE MESTRE EM CIÊNCIAS ANIMAIS.

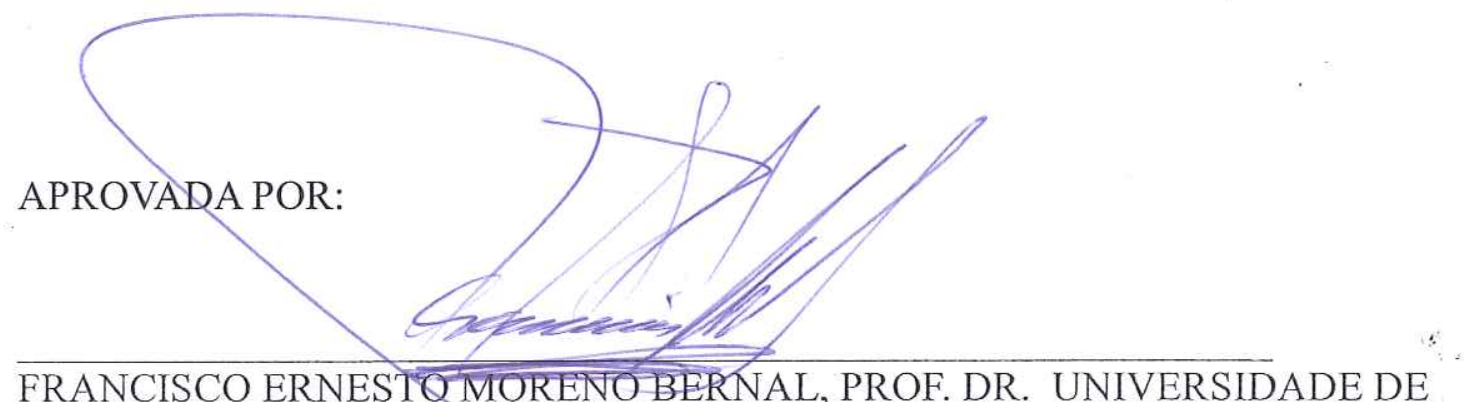
BRASILIA (UNB) (ORIENTADOR)

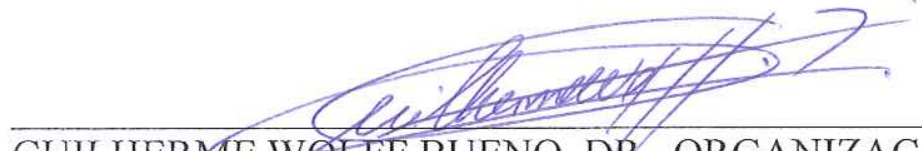

GUILHERME WOLFF BUENO, DR. ORGANIZAÇÃO DAS NAÇÕES UNIDAS PARA AGRICULTURA E ALIMENTAÇÃO(FAO)

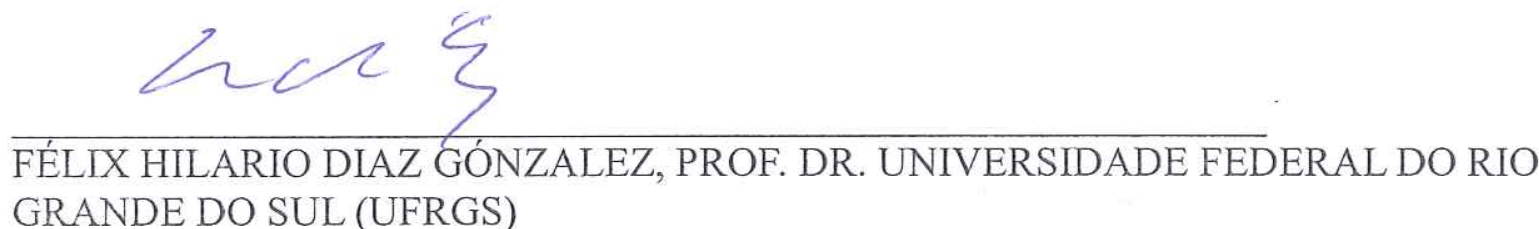




\section{AGRADECIMENTOS}

A Deus, que me ilumina e abençoa em todos os momentos.

Ao meu noivo, Leonardo pelo carinho, companheirismo, dedicação, paciência e apoio, fundamentais para concretização de mais esta etapa.

Aos meus pais, pelo apoio, dedicação e aprendizado, fundamentais na minha formação como ser humano.

Ao professor Francisco Bernal, pela acolhida e disposição em me orientar e dedicação ao ensino.

Ao professor Rodrigo Roubach pela inestimável co-orientação.

À SEAGRI-DF, representada pelo Lincoln, Ângelo, Leonardo e Fernando que me concederam a oportunidade de utilizar os espaços da Granja do Ipê e não mediram esforços na concretização deste trabalho.

Aos amigos Thiago Trombeta, Guilherme Wolff Bueno e Bruno Dallago pela inestimável ajuda técnica, acadêmica e pelos diálogos, conselhos e ponderações, que me ajudaram a concretizar esta dissertação.

E a todos que não foram citados aqui, mas que de alguma forma contribuíram para a concretização deste trabalho. 


\section{ÍNDICE}

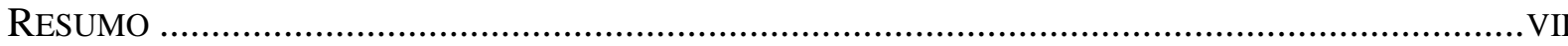

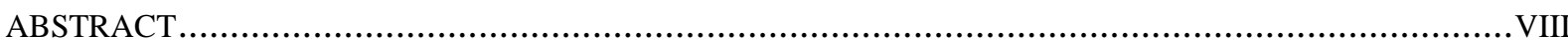

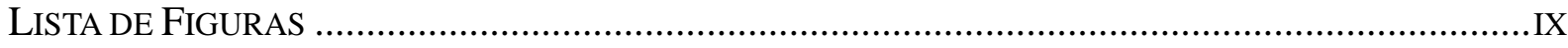

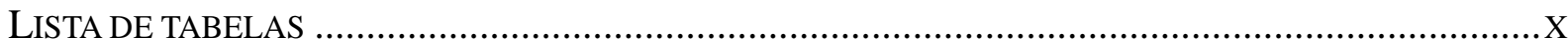

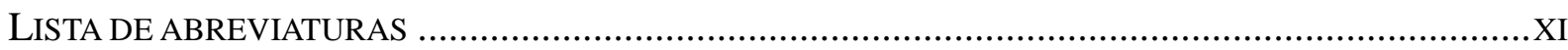

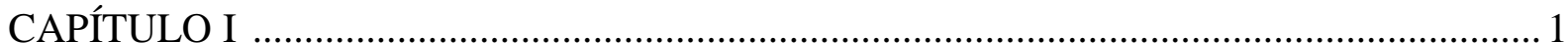

1- INTRODUÇÃ

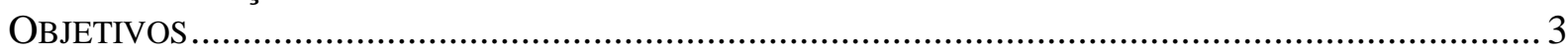

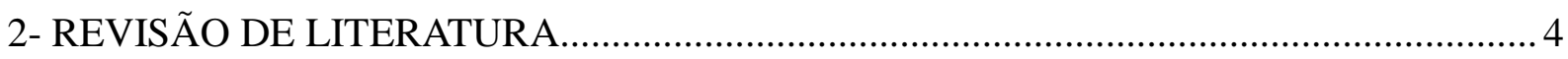

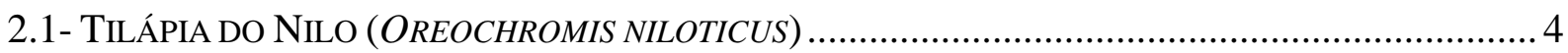

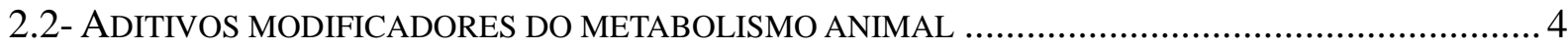

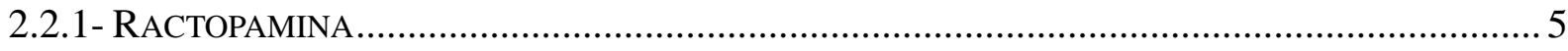

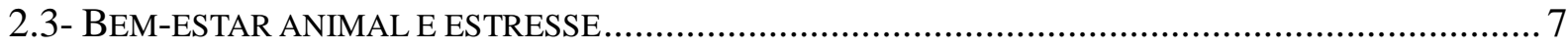

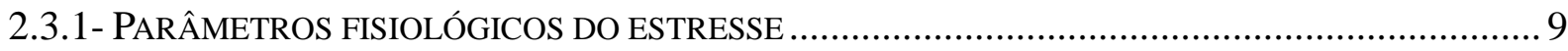

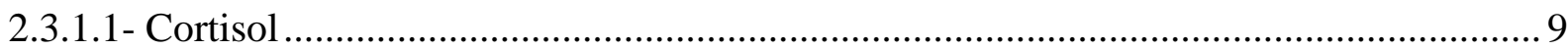

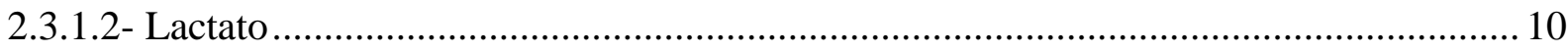

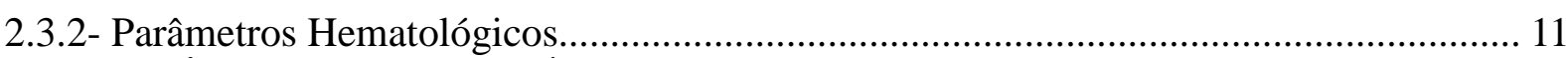

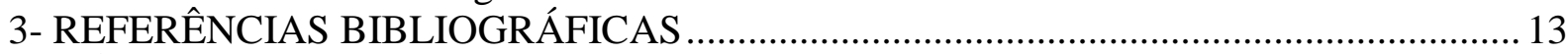

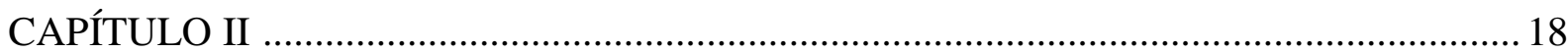

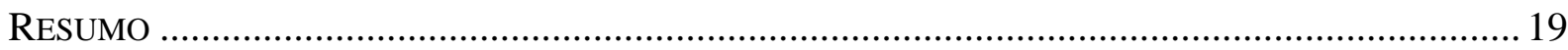

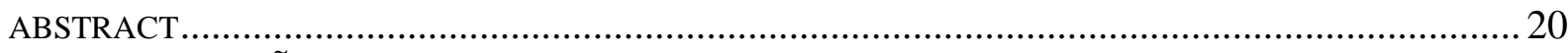

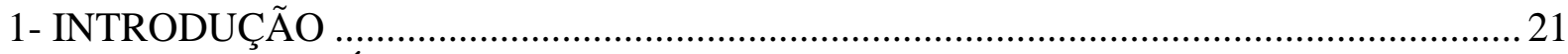

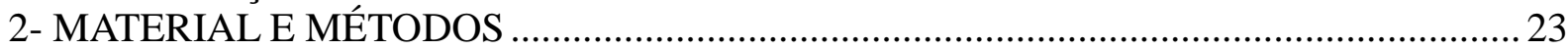

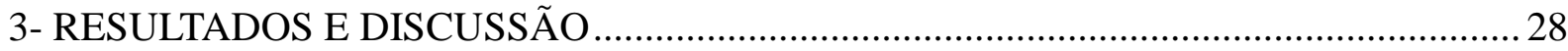

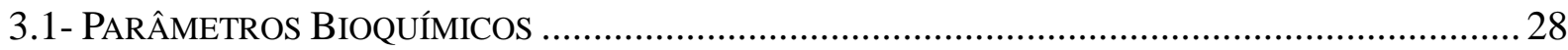

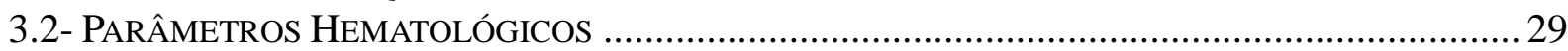

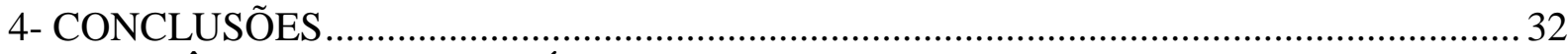

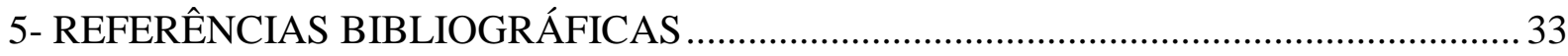




\title{
RESUMO
}

\section{INDICADORES HEMATOLÓGICOS E BIOQUÍMICOS DO ESTRESSE EM TILÁPIAS (Oreochromis niloticus) SUPLEMENTADAS COM RACTOPAMINA}

\author{
Ana Paula Pereira Mundim ${ }^{1}$ - 1 Faculdade de Agronomia e Veterinária (UNB), DF \\ Francisco Ernesto Moreno Bernal ${ }^{2}$ - 2 Faculdade de Agronomia e Veterinária (UnB), DF
}

Objetivou-se com este trabalho avaliar o efeito da ingestão de ractopamina nas concentrações 0 ppm (controle), 10 ppm, 20 ppm e 40 ppm na ração, sobre os parâmetros fisiológicos e imunológicos, por meio da analise dos parâmetros hematológicos e da concentração sérica de cortisol e lactato, em 80 tilápias do Nilo (Oreochromis niloticus) da linhagem GIFT, com peso médio de 500 gramas, distribuídas aleatoriamente em 16 caixas d'água, com capacidade para 500 litros, com a densidade de 5 animais. Retirando-se ao dia 01 animal de cada caixa e cada 20 dias, 2 peixes por caixa, totalizando 8 peixes de cada tratamento. Coletaram-se amostras de sangue para dosagem de cortisol, lactato e parâmetros hematológicos (contagem de hemácias, leucócitos, proteínas totais - PPT, volume globular - VG, hemoglobina. O lactato apresentou uma diminuição significativa $(\mathrm{p}<0,05)$ nos dois tempos de coleta com 10 ppm $(3,79 \mathrm{mmol} / \mathrm{L}$ aos 20 dias e 1,58 mmol/L aos 40 dias) e quando comparado ao controle (4,61 mmol/L ao dia 0, 4,78 mmol/L aos 20 dias e 4,54 aos 40 dias) e a mesma concentração diferiu quando comparada com 40 ppm de ractopamina aos 40 dias (3,15 mmol/L). Os parâmetros avaliados, cortisol, contagem de hemácias, leucócitos, volume globular - VG, hemoglobina, não apresentaram diferença significativa $(\mathrm{p}<0,05)$ entre tratamentos e tempos de coleta. Os resultados obtidos neste trabalho não demonstraram um estresse fisiológico produzido pela ingestão de ractopamina nas concentrações de 10, 20 e 40 ppm pelos animais. Entretanto, mais estudos acerca do tema devem ser realizados, para que o uso do aditivo seja recomendado de forma segura, quanto ao bem-estar dos peixes.

Palavras chave: Piscicultura, Tilápia do Nilo, bem-estar animal, Beta-adrenérgico. 


\title{
ABSTRACT \\ HEMATOLOGICAL AND BIOCHEMICAL INDICATORS OF STRESS IN TILAPIA (OREOCHROMIS NILOTICUS) SUPPLEMENTED WITH RACTOPAMINE
}

\author{
Ana Paula Pereira Mundim ${ }^{1-} 1$ - School of Agronomy and Veterinary Medicine (UNB), DF \\ Francisco Ernesto Moreno Bernal ${ }^{2-} 2$ - School of Agronomy and Veterinary Medicine (UNB), \\ Brasília - DF
}

The objective of this work to evaluate the effect of the ingestion of Ractopamine in $0 \mathrm{ppm}$ concentrations (control), $10 \mathrm{ppm} 20 \mathrm{ppm}$ and $40 \mathrm{ppm}$, in the feed, on the physiological and immunological parameters, through the analysis of hematological parameters and serum cortisol and lactate, in 80 Nile tilapias (Oreochromis niloticus) of the GIFT, with an average weight of 500 grams, randomly distributed in 16 water tanks with a capacity of 500 liters, with the density of 5 animals. By removing the day 01 animal of each box and every 20 days, fish 2 per box, total of 8 fish from each treatment. Collected blood samples for levels of cortisol, lactate and haematological parameters (red blood cells, leukocyte count, total protein-PPT, globular volume-VG, hemoglobin. Lactate showed a significant decrease (p < $0.05)$ in both times of collection with $10 \mathrm{ppm}(3.79 \mathrm{mmol} / \mathrm{L}$ to 20 days and $1.58 \mathrm{mmol} / \mathrm{L}$ to 40 days) and when compared to the control $(4.61 \mathrm{mmol} / \mathrm{L}$ to 0 day, $4.78 \mathrm{mmol} / \mathrm{L}$ to 20 days and 4.54 to 40 days) and the same concentration differed when compared with $40 \mathrm{ppm}$ of Ractopamine to 40 days $(3.15 \mathrm{mmol} / \mathrm{L})$. The parameters evaluated, cortisol, count of red blood cells, white blood cells, packed cell volume-VG, hemoglobin, showed no significant difference $(\mathrm{p}<0.05)$ between treatments and collection times. The results obtained in this study did not demonstrate a physiological stress produced by the ingestion of Ractopamine in concentrations of 10, 20 and 40 ppm for animals. However, more studies on the subject should be carried out so that the additive use is recommended securely on the welfare of fish.

Keywords: Fish farm, Nile tilapia, animal welfare, Beta-adrenergic. 


\section{LISTA DE FIGURAS}

CAPITULO I

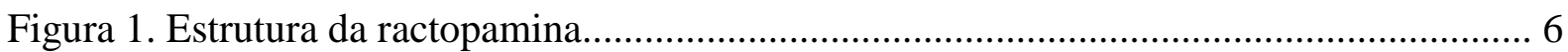

CAPITULO II

Figura 2. Local do experimento Núcleo de Tecnologia em Piscicultura e Pecuária da Secretaria de Estado da Agricultura, Abastecimento e Desenvolvimento Rural do Distrito Federal, localizado em Brasília-DF 23

Figura 2. Local do experimento Núcleo de Tecnologia em Piscicultura e Pecuária da Secretaria de Estado da Agricultura, Abastecimento e Desenvolvimento Rural do Distrito Federal, localizado em Brasília-DF 


\section{LISTA DE TABELAS}

\section{CAPITULO II}

Tabela 1 - Níveis de garantia das rações utilizadas para alimentação dos machos revertidos de de tilápia do Nilo durante o período experimental

Tabela 2 - - Médias e desvios padrão das concentrações de lactato e cortisol sanguíneos em tilápias do Nilo (Oreochromis niloticus) suplementadas com diferentes níveis de ractopamina na dieta

Tabela 3 - Médias e desvios padrão das concentrações dos parâmetros hematológicos de Tilápias suplementadas com diferentes níveis de ractopamina na dieta 
LISTA DE SÍMBOLOS E ABREVIAÇÕES

\author{
${ }^{\circ} \mathrm{C}$ - Graus Celsius \\ $\%$ - Porcentagem \\ RAC - Ractopamina \\ $\alpha-$ Alfa \\ $\beta-$ Beta \\ HTO - Hematócrito \\ Kg- Quilograma \\ $\mathrm{mg}$ - Miligrama \\ mL- Mililitros \\ L - Litros \\ mmol- MILIMOL
}


CAPITULO I 


\section{1- INTRODUÇÃO}

$\mathrm{Na}$ última década a aquicultura passou por um intenso processo de desenvolvimento. No Brasil, a atividade cresceu 56\% nos últimos 12 anos e tem se firmado cada vez mais em decorrência dos recursos hídricos disponíveis, clima favorável, mão de obra relativamente barata e crescente mercado interno, além de possuir cerca de 5,5 milhões de hectares de água, aproximadamente 208 reservatórios potenciais para a atividade e uma costa marítima de 8.000 (Bueno, 2015). Nesta década (MPA, 2010), o país chegou ao sexto lugar como produtor de tilápia cultivada no mundo, e a Tilápia do Nilo (Oreochromis niloticus) representou aproximadamente $47 \%$ da produção total de pescados em aquicultura de água doce.

A tilápia do Nilo (Oreochromis niloticus) é uma espécie de peixe precoce, que apresenta excelente desempenho em diferentes regimes de criação. Sua produção tem crescido acentuadamente, sendo hoje uma das espécies mais indicadas para o cultivo intensivo, devido às qualidades para a produção, bem como a excelente textura da carne (Furuya et al., 2010).

Apesar de inúmeras pesquisas na área de aquicultura, o conhecimento relacionado à nutrição de peixes ainda é escasso, quando comparado a outras espécies de importância zootécnica, onde a tecnologia é amplamente empregada nos estágios de formulação e manipulação de rações nutricionalmente eficientes (Pezzato et al., 2004). Um exemplo de tecnologia amplamente utilizado na produção de algumas espécies animais é o emprego de aditivos na ração (entre eles, antioxidantes, flavorizantes, modificadores metabólicos, promotores de crescimento, entre outros). Entre esses, está a ractopamina, um repartidor de energia, agonista $\beta$-adrenérgico $(\mathrm{A} \beta \mathrm{A})$, caracterizado como uma catecolamina sintética, conhecida por melhorar a eficiência alimentar, reduzir o conteúdo de gordura corporal e incrementar o crescimento muscular em animais. Uma substância exógena que altera a maneira como os nutrientes são particionados para depósito muscular ou de gordura 
(Mills; Spurlock; Smith, 2003).

Segundo Marchant-Forde et al. (2003), a suplementação com ractopamina pode ter efeito negativo sobre o bem-estar animal, gerando alterações fisiológicas típicas de estresse, que podem refletir na qualidade do produto final.

A maioria dos trabalhos realizados com ractopamina restringe-se a avaliações de desempenho, características de carcaça e qualidade de carne. No entanto, existem poucas informações na literatura demonstrando os efeitos deste aditivo sobre a susceptibilidade ao estresse dos animais, sobretudo em peixes, nos quais este aditivo não é usualmente utilizado, fazendo-se necessário um maior conhecimento para sua utilização segura.

\section{1- OBJETIVOS}

O presente experimento tem o objetivo avaliar o efeito da ingestão de ração contendo ractopamina nas concentrações de 10 ppm, 20 ppm e 40 ppm , sobre os parâmetros fisiológicos e imunológicos em tilápias do Nilo (Oreochromis niloticus) cultivadas em sistema de recirculação fechado. Como objetivos específicos têm-se:

1. Avaliar os parâmetros hematológicos em tilápias do Nilo (Oreochromis niloticus) submetidas a rações suplementadas com diferentes níveis de ractopamina.

2. Avaliar as concentrações séricas de cortisol e lactato em tilápias do Nilo (Oreochromis niloticus) submetidas a rações suplementadas com diferentes níveis de ractopamina. 


\section{2 - REVISÃO DE LITERATURA}

\section{1- Tilápia do Nilo (Oreochromis niloticus)}

A Tilápia do Nilo (Oreochromis niloticus) é considerada uma espécie de peixe exótica no Brasil. Proveniente da Costa de Marfim foi introduzida inicialmente no país, pelo Departamento Nacional de Obras Contra as Secas em 1971, visando o povoamento dos reservatórios públicos da região Nordeste (MPA 2010). Atualmente está entre o grupo das espécies mais cultivadas no mundo, se destacando principalmente em sistemas intensivos de produção (Furuya et al., 2010).

Trata-se de uma espécie onívora que se adapta a vários tipos de alimento, dócil ao manejo em todas as fases de cultivo, possui boa rusticidade, é prolífica, apresenta reprodução precoce e possui alta qualidade de carne (Tavares-Dias et al., 1999). Algumas habilidades adaptativas dessa espécie merecem destaque, como a resistência a enfermidades causadas por patógenos e a tolerância a baixos teores de oxigênio dissolvido na água (mínimo de $3 \mathrm{mg} / \mathrm{l}$ ) (Furuya et al., 2008).

$\mathrm{O}$ melhor desempenho produtivo é obtido em temperatura aquática entre $26^{\circ} \mathrm{C}$ e $28^{\circ} \mathrm{C}$, atingindo de 600 a 800 gramas entre 6 a 8 meses de cultivo. Possui filés de excelente qualidade, que correspondem a $30 \%$ da carcaça e tem como peculiaridade a ausência de espinhos em Y, apresentando ainda, sabor bastante atrativo ao paladar (Furuya et al., 2008).

\section{2 - Aditivos modificadores do metabolismo animal}

Frente à exigência dos consumidores modernos, referentes a mudanças nas preferências e nos hábitos alimentares, seja por maiores quantidades de cortes nobres ou por melhorias na qualidade da carne, têm-se adotado novas tecnologias na área de nutrição 
animal. Dentre essas tecnologias se destacam os aditivos alimentares (Mcgraw \& Liggett, 2005).

Aditivos são substâncias com propriedades funcionais digestivas ou equilibradoras da microbiota do trato digestório, que são adicionadas aos produtos ou água de consumo dos animais ou administrados diretamente por via oral (Heo et al., 2000). Os aditivos podem ainda ser referenciados como substâncias ou microrganismos adicionados intencionalmente aos alimentos com a finalidade de conservar, intensificar ou modificar suas propriedades. Dentre os aditivos, os modificadores metabólicos têm utilidade na produção animal, uma vez que possuem a capacidade de alterar o crescimento animal (Bridi et al., 2006).

Neste contexto, os aditivos modificadores do metabolismo animal podem alterar as taxas de síntese proteica, modificar a proporção da proteína em relação à gordura, alterar o perfil de ácidos graxos na carne ou alterar o metabolismo post mortem. Alguns modificadores metabólicos são compostos por vitaminas, metabólitos vitamínicos e compostos semelhantes à vitamina, que fornecem benefícios adicionais à carcaça quando adicionados além da exigência dos animais (Heo et al., 2000; Lawrence \& Coppack, 2000).

Apesar de as melhorias causadas pelos aditivos, alguns países, principalmente da União Europeia, não aceitam o uso destes produtos na criação animal. Os aditivos conhecidos como modificadores de carcaça são de grande interesse na produção animal, uma vez que possuem características capazes de alterarem o metabolismo, como a promoção de respostas celulares que resultam no aumento da deposição proteica e diminuição da quantidade de gordura (See; Armstrong; Weldon, 2008), entre eles, destaca-se a ractopamina. Este aditivo redireciona os nutrientes para o anabolismo proteico em detrimento do lipídico, contribuindo para a produção de carcaças com menor teor de gordura (Schinckel et al., 2003).

\section{3 - Ractopamina}

A ractopamina é um agonista beta-adrenérgico do grupo das fenetanolaminas, com estrutura análoga às catecolaminas epinefrina e norepinefrina. As fenetanolaminas fazem parte de uma classe de compostos que se ligam aos receptores $\alpha$ e $\beta$-adrenérgicos e são caracterizados pela presença de um anel aromático, uma cadeia lateral da etanolamina e o nitrogênio alifático (Bridi et al., 2006). 


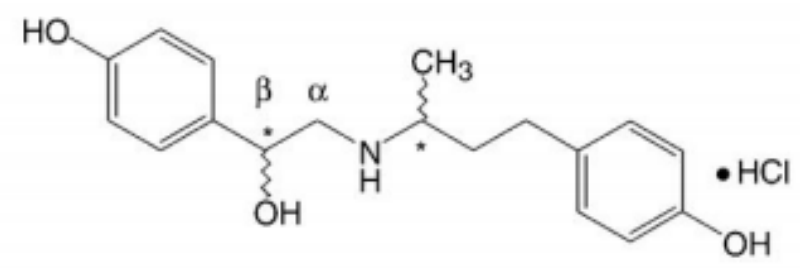

Figura 1 - Estrutura da ractopamina $\mathrm{HCl}$; * Carbonos quirais (Mills; Spurlock; Smith, 2003).

Classificada como um promotor de crescimento, por agir modificando o metabolismo animal, melhorando os índices de desempenho e as características de carcaça, ela foi amplamente pesquisada nos últimos 20 anos, e aprovada para uso em produção animal nos Estados Unidos e em vários outros países, como por exemplo, no Brasil, em 1999, como relatado pela FDA (Food And Drug Administration (2000)), (Schinckel et al., 2003; Bridi et al., 2006).

A ractopamina liga-se a receptores específicos existentes na superfície tanto de células musculares quanto adiposas no organismo, desencadeando uma cascata bioquímica de sinais no interior destas células (Bridi et al., 2006). O efeito primário da ractopamina é uma ativação muito específica da síntese de proteínas no tecido muscular, sem efeito sobre a taxa de degradação de proteínas. Segundo Dunshea et al. (1993), a taxa de síntese muscular pode ser aumentada em cerca de 30\% com o uso da ractopamina, resultando também em uma pequena redução da síntese de gordura aliada a um pequeno aumento na degradação de gorduras, ocasionando uma redução da deposição de gordura em cerca de $6 \%$. Isto é observado em diversas espécies de animais de produção, como suínos e ovinos (Bridi et al., 2006) e bovinos (Quinn et al., 2008 e Allen et al., 2009), e algumas espécies de peixes, como a truta arco-íris (Vandenberg \& Moccia, 1998). Nessa última, tem-se observado efeitos menos significativos em relação a mamíferos (Salem et al., 2006; Haji-Abadi, 2010).

Em geral a ractopamina é adicionada à ração e fornecida aos animais na fase de terminação, idade a qual já tenham atingido a maturidade, ou seja, quando a capacidade de retenção das proteínas começa a ser menor. Neste momento associa-se que os efeitos dos betaadrenérgicos sejam mais evidentes (Bridi et al., 2006).

Em peixes, a ractopamina tem sido pouco estudada, mas os resultados obtidos em sua maioria são condizentes com os efeitos observados em outras espécies, ou seja, é observado um aumento na taxa de crescimento, redução da gordura na carne e aumento da síntese proteica. Sendo observadas variações em função da dose, da espécie e do tempo de 
tratamento (Haji-Abadi, 2010).

Segundo Marchant-Forde et al. (2003), a suplementação com ractopamina pode ter efeito negativo sobre o bem-estar animal, como o aumento da concentração do cortisol, refletindo na qualidade do produto final.

\section{4 - Bem-estar animal e estresse}

De acordo com Hurnik (1992), o bem-estar animal é o estado de harmonia entre o animal e seu ambiente, caracterizado por condições físicas e fisiológicas ótimas e alta qualidade de vida do animal. Na área de produção animal, o termo está atrelado a outros conceitos como necessidades, liberdades, felicidade, adaptação, controle, capacidade de previsão, sentimentos, sofrimento, dor, ansiedade, medo, tédio, estresse, saúde e possibilidade de expressão do comportamento natural (Broom \& Molento, 2004).

Os fatores inerentes ao estresse estão entre os principais indicadores utilizados para avaliação do bem-estar animal. Vários autores descrevem que, animais sob estresse têm sua homeostasia ameaçada e em resposta a isso, desenvolvem mecanismos de adaptação (Pezzato et al., 2004). Esses mecanismos envolvem uma série de respostas neuroendócrinas e comportamentais, que visam manter o equilíbrio das funções vitais (Von-Borell, 1995).

As respostas ao estresse são divididas em primárias (neural e neuroendócrinas), secundárias (consequências fisiológicas resultantes das primárias) e terciárias (alterações comportamentais, diminuição de crescimento e aumento da suscetibilidade a doenças) (Bendhack, 2008). Entre os efeitos primários, encontra-se o aumento de catecolaminas (epinefrina e noradrenalina) e do cortisol no plasma. Entre as secundárias, estão as alterações da glicemia, do glicogênio hepático, glicogênio muscular, acumulo de ácido lático muscular, alterações no hematócrito, número de linfócitos, efeitos eletrolíticos (alterações nas concentrações plasmáticas de cloro, sódio, potássio, proteínas) e na osmolaridade do plasma. Os efeitos terciários principais são a redução de desempenho produtivo e reprodutivo e a diminuição da resistência às doenças (Wendelaar Bonga, 1997).

Silva et al. (2010) dividiram a reação aos estressores nos peixes em dois momentos: primeiro os efeitos que ameaçam ou perturbam o equilíbrio homeostático e, em seguida, o desencadeamento de diversas respostas fisiológicas compensatórias e adaptativas, visando a superação das ameaças.

Pode-se considerar que qualquer resposta não específica, ou o conjunto dessas, que ameacem o equilíbrio orgânico pode ser considerado estresse. Ou seja, o estresse pode ser 
referido como o somatório das mudanças que ocorrem no organismo de um peixe frente a um desafio, junto com a tentativa fisiológica de reestabelecer a homeostase (Barton, 1997; Wenderlaar Bonga, 1997).

A exposição aos agentes estressores pode se apresentar em diferentes intensidades, dependendo de fatores como espécie, condições ambientais, carga genética e também pode ter duração variável (Oliveira \& Galhardo, 2007). Desta forma, a exposição moderada a fatores estressantes costuma gerar nos peixes uma resposta adaptativa, restituindo o equilíbrio da homeostase. No entanto, caso seja um estresse intenso ou prolongado, o peixe não consegue se reestabelecer, podendo ocasionar consequências negativas para o seu estado de saúde (Barton, 2002).

Segundo Salonius \& Iwana (1993), o estresse pode ser diferenciado entre o estresse agudo e o estresse crônico. O primeiro, geralmente ocorre durante o manejo dos animais ou pela ocorrência de contatos repentinos com situações estressantes que levem os peixes a um estresse rápido. Este, geralmente cessa com o final do estímulo e os peixes se reestabelecem. $\mathrm{O}$ estresse crônico manifesta-se em condições as quais os peixes mantêm-se estressados permanentemente e, como consequência, geralmente há queda no rendimento produtivo e diminuição da resistência imunológica, podendo inclusive gerar doenças e mortalidade (Sanches, 2013).

$\mathrm{Na}$ piscicultura, as causas predisponentes do estresse incluem os fatores ambientais no sistema de criação, como as estações do ano, a idade do animal, condições fisiológicas, fatores sociais, características individuais, mudanças extremas no ambiente físico, captura, manejo e transporte (Wendelaar Bonga, 1997). Tais fatores, individualmente ou juntos, podem impor considerável estresse no sistema fisiológico do peixe, podendo causar manifestações em vários níveis de organização biológica (Barton, 1997).

Nos peixes, as ações dos agentes estressores causam distúrbios homeostáticos, desencadeando um conjunto coordenado de respostas fisiológicas e comportamentais, compensatórias ou adaptativas, possibilitando ao animal minimizar os efeitos impostos (Val et al. 2006). Entretanto, quando os mecanismos de respostas são forçados além de seus limites normais, a resposta pode ser deletéria a saúde dos animais, inclusive, com alterações a níveis populacionais, ocasionando severa mortalidade (Barton \& Iwana, 1997). Os peixes respondem ao estresse de forma a refletir a severidade e a duração do agente estressor (Barton, 1997). 


\section{5 - Parâmetros fisiológicos do estresse}

\subsection{1 - Cortisol}

Em peixes, o cortisol sanguíneo é o indicador de estresse mais utilizado, sendo o tamanho da resposta ao estresse, descrita como a elevação deste indicador em relação aos níveis basais. Assim, a severidade e duração da resposta primária ao estresse podem ser estimadas pelo monitoramento da flutuação da concentração deste hormônio no plasma (Barton et al., 2002).

A ação do cortisol no organismo dos peixes gera alterações bioquímicas e fisiológicas, por meio de suas funções mineralocorticoide e glicocorticoide. Atuando como mineralocorticoide, o cortisol altera a regulação osmótica e iônica causando um desequilíbrio iônico em peixes estressados. Este desequilíbrio é gerado pela captação de íons pelas brânquias induzida pelo cortisol, alterando o balanço hidromineral dos peixes. Este processo ocorre por meio da diferenciação de células de cloreto nas brânquias dos peixes e pela atividade da enzima sódio potássio adenosinatrifosfatase $(\mathrm{Na}+\mathrm{K}+-$ ATPase) que participa no transporte ativo de íons sódio e cloreto (Pickering, 1993; Laurent \& Perry, 1989; Wendelaar Bonga, 1997; Silva et al., 2012).

Atuando como glicocorticoide, o cortisol induz ao aumento dos níveis de glicose no sangue (hiperglicemia), e isto ocorre pela atividade de dois mecanismos: o estímulo da hidrólise das reservas de glicogênio no fígado (glicogenólise) e a indução do organismo a sintetizar glicose a partir de precursores não-carboidratos (gliconeogênese) (Pickering, 1993; Vijayan et al., 1991; Wendelaar Bonga, 1997).

Uma importante consequência da ação do cortisol como glicocorticoide é a lipólise, que degrada lipídeos, aumentando os níveis de ácidos graxos livres no sangue. Esta ocorrência, juntamente com a gliconeogênese, pode contribuir para a perda de peso durante um estresse crônico. Além disso, esta mobilização energética também pode resultar em efeitos deletérios na reprodução e redução no crescimento dos peixes (Sheridan, 1994).

$\mathrm{O}$ cortisol atua no sistema imunológico e na reação inflamatória em peixes. O sistema imunológico é deprimido pela ação do cortisol, pois este diminui a produção de interleucinas e reduz a mobilização de leucócitos e linfócitos circulantes (Oba et al., 2009). Quanto a resposta inflamatória em peixes, o cortisol inibe a formação de ácido araquidônico diminuindo a síntese de prostaglandinas pela via das ciclooxigenases, suprimindo a indução de inflamação (Bizarro, 2013). 
As brânquias, o intestino e o fígado são alvos importantes para o cortisol em peixes, os quais refletem as duas maiores ações desse hormônio, isto é, o controle do balanço hidromineral e do metabolismo energético. Assim, o cortisol em peixes combina ações comparáveis àquelas da aldosterona e de glicocorticóides em vertebrados terrestres. Outras ações do cortisol incluem redução na taxa de crescimento e supressão das funções imune e reprodutiva (Shaw \& Tume, 1992).

Grandin (1994) observou em seu estudo que em situações de extremo estresse, os valores de cortisol podem dobrar ou quadruplicar. Shaw \& Tume (1992), sugeriram que, na comparação de dois tratamentos, em relação ao estresse, o grupo que produzir cortisol em valores médios mais baixos deve ser adotado como o menos estressado.

Concentrações sanguíneas de cortisol em diferentes espécies de peixes geralmente se elevam alguns minutos após a exposição a um estressor agudo moderado, atingem um pico e retornam a valores basais dentro de, aproximadamente, 6 horas. Entre esses estressores estão as mudanças bruscas de temperatura, manejo, dentre outros fatores. Quando o agente estressor é crônico, a concentração de cortisol pode permanecer elevada, embora bem abaixo dos níveis mais altos (Shaw \& Tume, 1992).

Conforme relatado por Grandin et al. (1993), em salmonídeos, doses pequenas, mas cronicamente elevadas de cortisol têm implicações na depressão do sistema imunológico e na resistência a doenças.

\subsection{2 - Lactato}

Todas as células do organismo necessitam de energia para realizar os processos metabólicos básicos à sua sobrevivência (tipicamente sob a forma de adenosina-trifosfato, ATP). Esta energia celular é produzida por três grandes processos: a glicólise, o ciclo de Krebs e a fosforilação oxidativa (Guyton \& Hall, 2003; Acierno \& Mitchell, 2007). O lactato é um produto final da glicólise anaeróbica que ocorre em tecidos hipóxicos (Poli et al., 2005).

O lactato produzido pelos eritrócitos, difunde-se para fora das células e é transportado a outros tecidos que são capazes de o utilizar na produção de energia. Nos rins, coração e fígado, o lactato é convertido em piruvato, que segue o seu percurso metabólico, sendo transportado para o interior das mitocôndrias para produzir energia. No fígado e nos rins, o mesmo lactato pode ser convertido em glicose através de um processo designado por neoglicogênese. A glicose produzida pode então ser armazenada sob a forma de glicogénio ou lançada na corrente sanguínea para uma posterior utilização por outras células e tecidos 
(Guyton \& Hall, 2003; Bolton, 2007).

Se a conversão de piruvato em lactato ocorre de forma mais ou menos contínua em situações de hipóxia tecidual, a concentração de lactato aumenta e a relação lactato/piruvato tende a aumentar (Bolton, 2007). O aumento da concentração intracelular de lactato faz com que este se desloque para a corrente sanguínea. Caso as condições anaeróbias persistam, ocorre uma sobrecarga generalizada e os tecidos que anteriormente eram capazes de reciclar este mesmo lactato deixam de ser. Situações de estresse intenso podem levar à exaustão muscular. Neste caso, haverá degradação intensa do glicogênio muscular, formando grandes quantidades de ácido lático que será liberado na corrente sanguínea, por isso, o lactato é um bom indicador de estresse por hipóxia (Barton et al., 2002).

Alterações nos parâmetros sanguíneos relacionados aos níveis de hemoglobina, lactato e glicose podem estar relacionados a adaptações fisiológicas ao estresse ou anóxia, demonstrando a saúde e situação fisiológica do animal (Grandin et al., 1994; Barton et al., 2002).

O início e desenvolvimento do rigor mortis está diretamente relacionado à diminuição do índice de frescor do peixe. Uma estreita relação observada entre resposta aguda ao estresse e processos bioquímicos post mortem dos peixes sugere o uso concomitante dos indicadores hematológicos de estresse, como cortisol do plasma, lactato e glicose, com os indicadores de estresse no tecido, tais como pH muscular, lactato e ATP e seus catabólitos para uma completa avaliação dos efeitos do estresse (Poli et al., 2005).

\section{6 - Parâmetros Hematológicos}

A hematologia estuda a morfologia, bioquímica e função das células sanguíneas, bem como os órgãos que as produzem e o efeito de doenças em tais parâmetros. Ocorrem variações morfológicas e quantitativas dos elementos sanguíneos frente a condições endógenas e exógenas. Em peixes, a hematologia contribui para a compreensão da físiologia comparativa, relação filogenética, condições alimentares e outros parâmetros ecológicos (Campbell, 1990).

O meio-ambiente influencia o perfil sanguíneo do peixe, sendo utilizado para monitorar a resposta frente a uma situação de estresse (Wells et al. 2005). Índices hematológicos são importantes parâmetros para a avaliação do estado físiológico e no controle de patologias do estresse em peixes, e as variações destes dependem da espécie, idade e condições de saúde, sendo também influenciadas pelo sexo (Tavares-Dias et al., 
1999).

Os peixes apresentam eritrócitos ovais ou elípticos, com núcleo central acompanhando o formato da célula, com cromatina compactada e sem nucléolos (Campbell, 1990). Os eritrócitos podem variar entre as espécies, ocorrendo padrões de atividades diferentes de acordo com seus hábitos de vida (Wells et al. 2005; Tavares-Dias et al. 2008). A quantificação dos eritrócitos pode indicar a existência de anemia ou policitemia provenientes do estresse e indicar respostas a estímulos externos (Tavares-Dias \& Moraes, 2004; Pedro et al. 2005).

O hematócrito corresponde ao volume ocupado pelos eritrócitos em uma quantidade de sangue total. Em geral o VG de peixes apresenta menor valor que em mamíferos e aves, com variação entre espécies (Campbell, 1988). É o índice do eritrograma com menor coeficiente de variação, sendo assim, bom indicador de efeitos para os diversos fatores ambientais a que os peixes estão submetidos (Tavares-Dias \& Moraes, 2004).

A hemoglobina, pigmento respiratório dos eritrócitos, tem por função transportar o $\mathrm{O}_{2}$ e parte do $\mathrm{CO}_{2}$ no sangue (Ranzani et al. 2004). A hemoglobina apresenta diferenças ainda em relação à sua capacidade de tamponamento e variações da afinidade pelo oxigênio (Val et al. 1996). As atividades eritropoiéticas relacionadas ao número de eritrócitos, concentração de hemoglobina e VG são indicadores da capacidade do transporte de oxigênio, hipóxia, exercício, estresse induzido, estágio reprodutivo e variações sazonais (Tavares-Dias \& Moraes, 2004; Wells et al. 2005).

Em relação às células da série branca dos peixes, de acordo com Vosyliené (1999), a variação do número de leucócitos circulantes pode ser atribuída a uma resposta generalizada do sistema imune, acionado pelo estresse fisiológico e consequente estado de saúde afetado. O aumento de leucócitos pode ser observado no início de um estresse na maioria das espécies de peixes, sendo considerado como uma tentativa de recuperar a homeostase em desequilíbrio, ao mesmo tempo em que o decréscimo na contagem de leucócitos pode ser atribuído ao enfraquecimento do sistema imunológico (Wells et al. 2005). 


\section{3 - REFERÊNCIAS BIBLIOGRÁFICAS}

ACIERNO, M. J.; MITCHELL M. A. Evaluation of four point-of-care meters for determination of blood lactate concentrations in dogs, Journal of the American Veterinary Medical Association, 230(9), 1315-1318, 2007.

ALLEN J. D.; FAHEY, B. F.; TRAHEY, G. E. Effect of preslaughter feeding and ractopamine hydrochloride supplementation on growth performance, carcass characteristic, and end product quality in market dairy cows. Journal of Animal Science, Champaing, v. 82, n. 11, p. 2400-2408, July 2009.

BARTON, B. A.; IWAMA, G. K. Physiological changes in fish from stress in aquaculture with emphasis on the response and effects of corticosteroids. Reviews of Fish Diseases, 1: 326. 1991.

BARTON, B. A. Stress in finfish: past, present and future a historical perspective. In: Iwama, G.K., Pickering, A.D., Sumpter, J.P., Schreck, C.B. (Eds.). Fish stress and health in aquaculture. Society for Experimental Biology Seminar Series 62. Cambridge University Press, New York, NY. p.1-33, 1997.

BARTON, B. A.; MORGAN, J. D.; VIJAYAN, M. M. Physiological and condition-related indicators of environmental stress in fish. $I n$ : Adams (ed.). Biological indicator of aquatic ecosystem stress, Bestherda, Maryland, American Fisheries Society, p.289-320, 2002.

BENDHACK, F. Respostas fisiológicas do matrinxã Brycon amazonicus após mudança de ambientes com diferentes concentrações de sais de cálcio e de sódio. 2008.

BOLTON, J. D. Clinical use of lactate testing in shock states, Seminars in Anaesthesia, Perioperative Medicine and Pain, 26, 35-39, 2007.

BUENO, F. R.; DE CARVAlHO GOMES, L.; CHAGAS, E. C. Respostas de estresse em pirarucu (Arapaima gigas) durante práticas de rotina em piscicultura. Acta Amazonica, v. 36, n. 3, p. 349, 2015.

BRIDI, A. M.; OLIVEIRA, A. R.; FONSECA, N. A. N. Efeito do genótipo halotano, da ractopamina e do sexo do animal na qualidade da carne suína. Revista Brasileira de Zootecnia, Viçosa, v.35, p.2027-2033, 2006. 
BROOM, D. M.; MOLENTO C. F. M. Bem-estar animal: conceito e questões relacionadas: revisão. Archives of Veterinary Science, Curitiba, v. 9, p. 1-11, 2004.

CAMPBELL, T.W.; MURRU, F. An introduction to fish hematology. Compendium of Continuing Education in Veterinary Science, v. 12, p. 525-533, 1990.

FOOD AND DRUG ADMINISTRATION. Freedom of information summary. New Hampshire, 2000.2 Disponível em <http://www.fda.gov/downloads/AnimalVeterinary/Products/AprrovedAnimalIDrugProducts/ FOIADrugSummaries/ucm117246.pdf>. Acesso em 25 Out. 2013.

FURUYA, W. M.; PEZZATO, L. E.; BARROS, M. M. Use of ideal protein concept for precision formulation of amino acids level in diets with and without di calcium phosphate for juvenile Nile tilapia. Aquaculture Research. v. 35, p. 110-116, 2010.

GRANDIN, T. Farm animal welfare during handling, transport, and slaughter. Journal American Veterinary Medical Association, Schaumburg, v. 204, p. 372-376, 1994.

GUYTON, A.C.; HALL, J.E. (2003). Chapter 72, Energetic and metabolic rate - adenosine triphosphate function as an energy currency in metabolism. In textbook of medical physiology, 11th Edition, Elsevier - Saunders. 881-883. Philadelphia.

HAJI-ABADI, J. Sayed Mohammad Ali et al. Effects of supplemental dietary 1-carnitine and ractopamine on the performance of juvenile rainbow trout, Oncorhynchus mykiss. Aquaculture Research, v. 41, n. 11, p. 1582-1591, 2010.

HEO, K. N.; ODLE, J.; HAN, I. K.; CHO, W. T.; SEO, S. W.; HEUGTEN E.; VAN \& PILKINGTON, D.H. Dietary L-carnitine improves nitrogen utilization in growing pigs fed low energy, fat-containing diets. J. Nutr. 2000.

HURNIK, J. F. Behaviour (Chapter 13). In: PHILLIPS, C.; PIGGINS, D. (Eds.). Farm animals and the environment. Wallingford : CAB International, p. 235-244. 1992.

LAURENT, P.; PERRY, S. F. Adaptational responses of rainbow trout to lowered external $\mathrm{NaCl}$ concentration: contribution of the branchial chloride cell. Journal of Experimental Biology, v. 147, n. 1, p. 147-168, 1989.

LAWRENCE VJ, COPPACK SW: The endocrine function of the fat cell-regulation by the sympathetic nervous system. Horm Metab Res 32: 453-467, 2000.

MARCHANT-FORDE, J. N.; LAY, D. C. JR.; PAJOR, E. A. The effects of ractopamine on the behavior and physiology of finishing pigs. Journal of Animal Science, v.81, p. 416-422, 2003.

MCGRAW, D. W.; LIGGETT, S. B. Molecular mechanisms of beta2- adrenergic receptor function and regulation. Proceedings of the American Thoracic Society, Stanford, v. 2, n. 4, p. 292-296, 2005. 
MILLS, S. E.; SPURLOCK, M. E.; SMITH, D. J. Beta-adrenergic receptor subtypes that mediate ractopamine stimulation of lipolysis. Journal of Animal Science, Champaign, v. 81, n. 3, p. 662-668, 2003.

MPA. Ministério da Pesca e Aquicultura., 2010. Boletim estatístico da pesca e aquicultura 2010- Brasil. Disponible en: <http://www.mpa.gov.br> Acesso: 02 Out. 2014.

OBA, E. Fish leukocyte responses. In: Feldman, B.F.; Zinkl, J.G.; Jain, N.C. Veterinary hematology, (Ed. Fifth). P.436-439. 2009.

OLIVEIRA, R. F.; GALHARDO, L. Sobre a aplicação do conceito de bem-estar a peixes teleósteos e implicações para a piscicultura. R. Bras. Zootec, v. 36, p. 77-86, 2007.

PEDRO, N.; GUIJARRO, A.I.; LOPEZ-PATIÑO, M.A.; MARTINEZ-ALVAREZ, R.; DELGADO, M.J. Daily and seasonal variations in haematological and blood biochemical parameters in the tench, Tinca tinca Linnaeus, 1758. Aquaculture Research, v.36, n. 12, p. 1185-1196, 2005.

PEZZATO, L. E.; BARROS, M. M.; FRACALOSSI, D. M. et al. Nutrição de peixes. In: CYRINO, J. E. P.; URBINATI, E. C.; FRACALOSSI, D. M. (Ed.). Tópicos especiais em piscicultura de água doce tropical intensiva, São Paulo: Aquabil, p.75-172. 2004.

PICKERING, A. D. Growth and stress in fish production. Aquaculture, v.111, p.51-63. 1993.

QUINN, M. J.; SEE, M. T.; WELDON, W. C. The effects of ractopamine-hydrogen chloride (Optaflexx) on performance, carcasscharacteristics, and meat quality of finishing feedlot heifers. Journal of Animal Science, Champaing, v. 86, n. 4, p. 902-908, Apr. 2008.

RANZANI-PAIVA, M.J.; SILVA-SOUZA, A.T. Hematologia de peixes brasileiros. In: RANZANI-PAIVA, M.J.; TAKEMOTO, R.M.; LIZAMA, M.A.P. (Eds.). Sanidade de Organismos Aquáticos. São Paulo: Varela, 2004. p. 89-120.

SALEM, M.; LEVESQUE, H.; MOON, T. W. Anabolic effects of feeding b2-adrenergic agonist on rainbow trout muscle proteases and proteins. Comparative Biochemistry and Physiology Part A: Molecular \& Integrative Physiology. New York, v. 144, p. 145-154, July 2006.

SANCHES, F. H. C. Resposta de estresse à substância de alarme na tilápia-do-nilo. 2013. 28f. Dissertação (Mestrado em Ciências Biológicas - Zoologia) - Instituto de Biociências de Botucatu, Universidade Estadual Paulista. 2013.

SALONIUS, K.; IWAMA, G. K. Effects of early rearing environment on stress response, immune function, and disease resistance in juvenile coho (Oncorhynchus kisutch) and chinook salmon (O. tshawytscha). Canadian Journal of Fisheries and Aquatic Sciences, v. 50, n. 4, p. 759-766, 1993.

SCHINCKEL, A. P. Development of a model to describe the compositional growth and dietary lysine requirements of pigs fed ractopamine. Journal of Animal Science, v. 81, n. 5, p. 1106-1119, 2003. 
SEE, M.T.; ARMSTRONG, T.A.; WELDON, W.C. Effect of a ractopamina feeding program on growth performance and carcass composition in finishing pigs. Journal of Animal Science, v.82, n.8, p.2474-2480, 2004.

SHAW, F. D.; TUME, R. K. The Assessment of Pre-slaughter and Slaughter Treatments of Livestock by Measurement of Plasma Constituents - A Review of Recent Work. Meat Science, Barking, v. 32, p. 311-329, 1992.

SHAW, F. D.; TROUT, G. R. Plasma and Muscle Cortisol Measurements as Indicators of Meat Quality and Stress in Pigs. Meat Science, Barking, v. 39, p. 237- 246, 1995.

SILVA, R. D. SILVA; ROCHA, L. O.; FORTES, B. D. A.; RODRIGUES, C. P. F.; LOBO, J. R.; FALEIRO, M. B. R.; DE PAULA, F. G.; VIEIRA, D. Determinação de glicose plasmática em exemplares adultos de Tilápia Oreochromis niloticus) por glicosímetro digital portátil e por método enzimático. In: Congresso de Ensino Pesquisa e Extensão, 6., 2009, Goiânia. Anais... Goiânia: UFG, 2010, p. 5914-5919.

SILVA, R. D.; ROCHA L. O.; FONTES D. A.; VIERA D.; FIORAVANTI M. C. Parâmetros hematológicos e bioquímicos da tilápia-do-Nilo (Oreochromis niloticus L.) sob estresse por exposição ao ar. Pesqui. Vet. bras, v. 32, n. supl. 1, p. 99-107, 2012.

TAVARES-DIAS, M.; MORAES, F.R.; MARTINS, M.L.; KRONKA, S.N. Fauna parasitária de peixes oriundos de pesque-pagues do município de Franca, São Paulo, Brasil. II. Metazoários. Revista Brasileira de Zoologia, 18: 81-95. 1999

TAVARES-DIAS, M.; MORAES, F. R. Características hematológicas da Tilapia rendalli capturada em "pesque-pague" de Franca, São Paulo, Brasil. Bioscience Journal, Uberlândia, v.19, p. 103-110, 2004.

TAVARES-DIAS, M.; MORAES, F. R. Hematologia de peixes teleósteos. Ed. Eletrônica e Arte Final. Ribeirão Preto-SP. 144 páginas, 2005.

TAVARES-DIAS, M.; MORAES, F. R.; MARTINS, M. L., Hematological assessment in four Brazilian teleost fish with parasitic infections, collected in feefishing from Franca, São Paulo, Brazil. Boletim do Instituto de Pesca, v. 34, n. 2, p. 189-196, 2008.

VAL, A.L.; MENEZES, A.C.L.; FERREIRA, M.S.; SILVA, M.N.P. da; ARAÚJO, R.M.; VAL, V.M.F. Estresse em peixes: respostas integradas para a sobrevivência e da adaptação. In: SOUZA-SILVA, A.T. Sanidade de Organismos Aquáticos no Brasil. SANIDADE II, Maringá, PR: Abrapoa, 2006, p. 387.

VANDERBERG, G.W.; LEATHERLAND, J.F.; MOCCIA, R.D. The effects of the betaagonist ractopamine in growth hormone and in intermediate metabolite concentrations in rainbow trout, Oncorhynchus mykiss. Aquac. Res., v.29, p79-87, 1998.

VIJAYAN, M. M.; MOMMSEN, T. P.; GLEMET, H. C.; MOON, T. W.. Metabolic effects of cortisol treatment in a marine teleost, the sea raven. The Journal of experimental biology, $v$. 199, n. 7, p. 1509-1514, 1991. 
VON-BORELL, E. Neuroendocrine integration of stress and significance of stress for the performance of farm animals. Applied Animal Behaviour Science, Amsterdam, v. 44, p. 219-227, 1995.

VOSYLIENÉ, M. Z., The effects of heavy metals on haematological indices of fish(Survey). Acta Zoologica Lituanica. v. 9, p.76-82, 1999.

WELLS, R.M.G.; BALDWINS, J.; SEYMOUR, R.S.; CHRISTIAN, K.; BRITTAIN, T. Red blood cell function and haematology in two tropical freshwater fishes from Australia. Comparative Physiology and Biochemistry, v. 141, p. 87-93, mai. 2005.

WENDELAAR BONGA, S.E. The stress response in fish. Physiol. Rev., v.77, p.591-625, 1997. 


\section{CAPÍTULO II}

AVALIAÇÃO DOS INDICADORES HEMATOLÓGICOS E BIOQUÍMICOS DO ESTRESSE EM TILÁPIAS (Oreochromis niloticus), SUPLEMENTADAS COM RACTOPAMINA 


\section{AVALIAÇÃO DOS INDICADORES HEMATOLÓGICOS E BIOQUÍMICOS DO ESTRESSE EM TILÁPIAS (Oreochromis niloticus), SUPLEMENTADAS COM RACTOPAMINA}

\section{RESUMO}

Objetivou-se com este trabalho avaliar o efeito da ingestão de ractopamina nas concentrações 0 ppm (controle), 10 ppm, 20 ppm e 40 ppm na ração, sobre os parâmetros fisiológicos e imunológicos, por meio da analise dos parâmetros hematológicos e da concentração sérica de cortisol e lactato, em 80 tilápias do Nilo (Oreochromis niloticus) da linhagem GIFT, com peso médio de 500 gramas, distribuídas aleatoriamente em 16 caixas d'água, com capacidade para 500 litros, com a densidade de 5 animais. Retirando-se ao dia 01 animal de cada caixa e cada 20 dias, 2 peixes por caixa, totalizando 8 peixes de cada tratamento. Coletaram-se amostras de sangue para dosagem de cortisol, lactato e parâmetros hematológicos (contagem de hemácias, leucócitos, proteínas totais - PPT, volume globular - VG, hemoglobina. O lactato apresentou uma diminuição significativa $(\mathrm{p}<0,05)$ nos dois tempos de coleta com $10 \mathrm{ppm}(3,79 \mathrm{mmol} / \mathrm{L}$ aos 20 dias e $1,58 \mathrm{mmol} / \mathrm{L}$ aos 40 dias $)$ e quando comparado ao controle $(4,61 \mathrm{mmol} / \mathrm{L}$ ao dia 0, 4,78 mmol/L aos 20 dias e 4,54 aos 40 dias) e a mesma concentração diferiu quando comparada com 40 ppm de ractopamina aos 40 dias (3,15 mmol/L). Os parâmetros avaliados, cortisol, contagem de hemácias, leucócitos, volume globular - VG, hemoglobina, não apresentaram diferença significativa $(\mathrm{p}<0,05)$ entre tratamentos e tempos de coleta. Os resultados obtidos neste trabalho não demonstraram um estresse fisiológico produzido pela ingestão de ractopamina nas concentrações de 10, 20 e 40 ppm pelos animais. Entretanto, mais estudos acerca do tema devem ser realizados, para que o uso do aditivo seja recomendado de forma segura, quanto ao bem-estar dos peixes.

Palavras chave: Piscicultura, Tilápia do Nilo, bem-estar animal, Beta-adrenérgico. 


\section{ABSTRACT \\ HEMATOLOGICAL AND BIOCHEMICAL INDICATORS OF STRESS IN TILAPIA (OREOCHROMIS NILOTICUS) SUPPLEMENTED WITH RACTOPAMINE}

The objective of this work to evaluate the effect of the ingestion of Ractopamine in $0 \mathrm{ppm}$ concentrations (control), $10 \mathrm{ppm} 20 \mathrm{ppm}$ and $40 \mathrm{ppm}$, in the feed, on the physiological and immunological parameters, through the analysis of hematological parameters and serum cortisol and lactate, in 80 Nile tilapias (Oreochromis niloticus) of the GIFT, with an average weight of 500 grams, randomly distributed in 16 water tanks with a capacity of 500 liters, with the density of 5 animals. By removing the day 01 animal of each box and every 20 days, fish 2 per box, total of 8 fish from each treatment. Collected blood samples for levels of cortisol, lactate and haematological parameters (red blood cells, leukocyte count, total protein-PPT, globular volume-VG, hemoglobin. Lactate showed a significant decrease ( $\mathrm{p}<$ $0.05)$ in both times of collection with $10 \mathrm{ppm}(3.79 \mathrm{mmol} / \mathrm{L}$ to 20 days and $1.58 \mathrm{mmol} / \mathrm{L}$ to 40 days) and when compared to the control $(4.61 \mathrm{mmol} / \mathrm{L}$ to 0 day, $4.78 \mathrm{mmol} / \mathrm{L}$ to 20 days and 4.54 to 40 days) and the same concentration differed when compared with $40 \mathrm{ppm}$ of Ractopamine to 40 days $(3.15 \mathrm{mmol} / \mathrm{L})$. The parameters evaluated, cortisol, count of red blood cells, white blood cells, packed cell volume-VG, hemoglobin, showed no significant difference $(\mathrm{p}<0.05)$ between treatments and collection times. The results obtained in this study did not demonstrate a physiological stress produced by the ingestion of Ractopamine in concentrations of 10, 20 and $40 \mathrm{ppm}$ for animals. However, more studies on the subject should be carried out so that the additive use is recommended securely on the welfare of fish.

Keywords: Fish farm, Nile tilapia, animal welfare, Beta-adrenergic. 


\section{1 - INTRODUÇÃO}

A tilápia do Nilo (Oreochromis niloticus) está entre os peixes mais cultivados mundialmente, fato devido a sua rusticidade, precocidade sexual, rápido crescimento e, principalmente, por sua carne ser tão apreciada pelo consumidor, devido ao sabor suave e a fácil remoção de espinhas.

O mercado de peixes vem se tornando cada vez mais exigente e crescente, o peso médio de abate comercial de tilápias vem aumentando, o que consequentemente ocasiona em um maior teor de gordura depositada na carcaça, a qual é indesejada por esse novo mercado consumidor, que é mais informado e busca uma alimentação mais saudável. A procura por carnes magras e com pouca gordura aumentou nos últimos anos, fazendo com que novas opções sejam estudadas e avaliadas durante a produção de animais. Dentre elas os aditivos alimentares, principalmente os modificadores de carcaça que se destacam por conferir melhorias ao produto final.

A utilização do $\beta$-agonista ractopamina como promotor de crescimento em dietas para animais melhora o desempenho da produção e as características da carcaça de diversas espécies domésticas. Esses agonistas por meio da aceleração e modificação de vias metabólicas específicas, principalmente as relacionadas com o metabolismo das proteínas e dos lipídeos.

Em granjas de suínos a utilização do cloridrato de ractopamina na dieta, tornou-se indispensável para praticamente toda produção comercial nacional, exceto em animais destinados a exportação para países específicos como os da União Europeia.

Já para animais aquáticos, como os peixes, existem poucos estudos sobre os efeitos e níveis adequados de ractopamina na dieta. Em geral a ractopamina é adicionada à ração e fornecida aos animais na fase de terminação, idade a qual já tenham atingido a maturidade, ou seja, quando a capacidade de retenção das proteínas começa a ser menor. Neste momento associa-se que os efeitos dos beta-adrenérgicos sejam mais evidentes. 
O estresse em piscicultura intensiva pode ser proveniente de várias fontes, das quais são práticas comumente utilizadas, como por exemplo, a manipulação dos animais, o emprego de alta densidade de estocagem, o transporte, interações biológicas, qualidade da água, manejo de alimentação, incluindo a utilização de aditivos nutricionais. a suplementação com ractopamina pode ter efeito negativo sobre o bem-estar animal, gerando alterações fisiológicas típicas de estresse, que podem refletir na qualidade do produto final.

A maioria dos trabalhos realizados com ractopamina restringe-se a avaliações de desempenho, características de carcaça e qualidade de carne. No entanto, existem poucas informações na literatura demonstrando os efeitos deste aditivo sobre a susceptibilidade ao estresse dos animais, sobretudo em peixes, nos quais este aditivo não é usualmente utilizado, fazendo-se necessário um maior conhecimento para sua utilização segura. Portanto, o presente trabalho objetivou-se avaliar o efeito da ingestão de ractopamina na ração, sobre os parâmetros fisiológicos e imunológicos em tilápias do Nilo da linhagem GIFT, avaliando os parâmetros hematológicos e a concentração sanguínea de cortisol e lactato. 


\section{2 - MATERIAL E MÉTODOS}

O experimento foi realizado no Núcleo de Tecnologia em Piscicultura e Pecuária da Secretaria de Estado da Agricultura, Abastecimento e Desenvolvimento Rural do Distrito Federal, localizado em Brasília-DF. As análises bioquímicas e hematológicas foram realizadas no Laboratório de Patologia Clínica Veterinária e Laboratório de Bem-estar Animal da Universidade de Brasília.

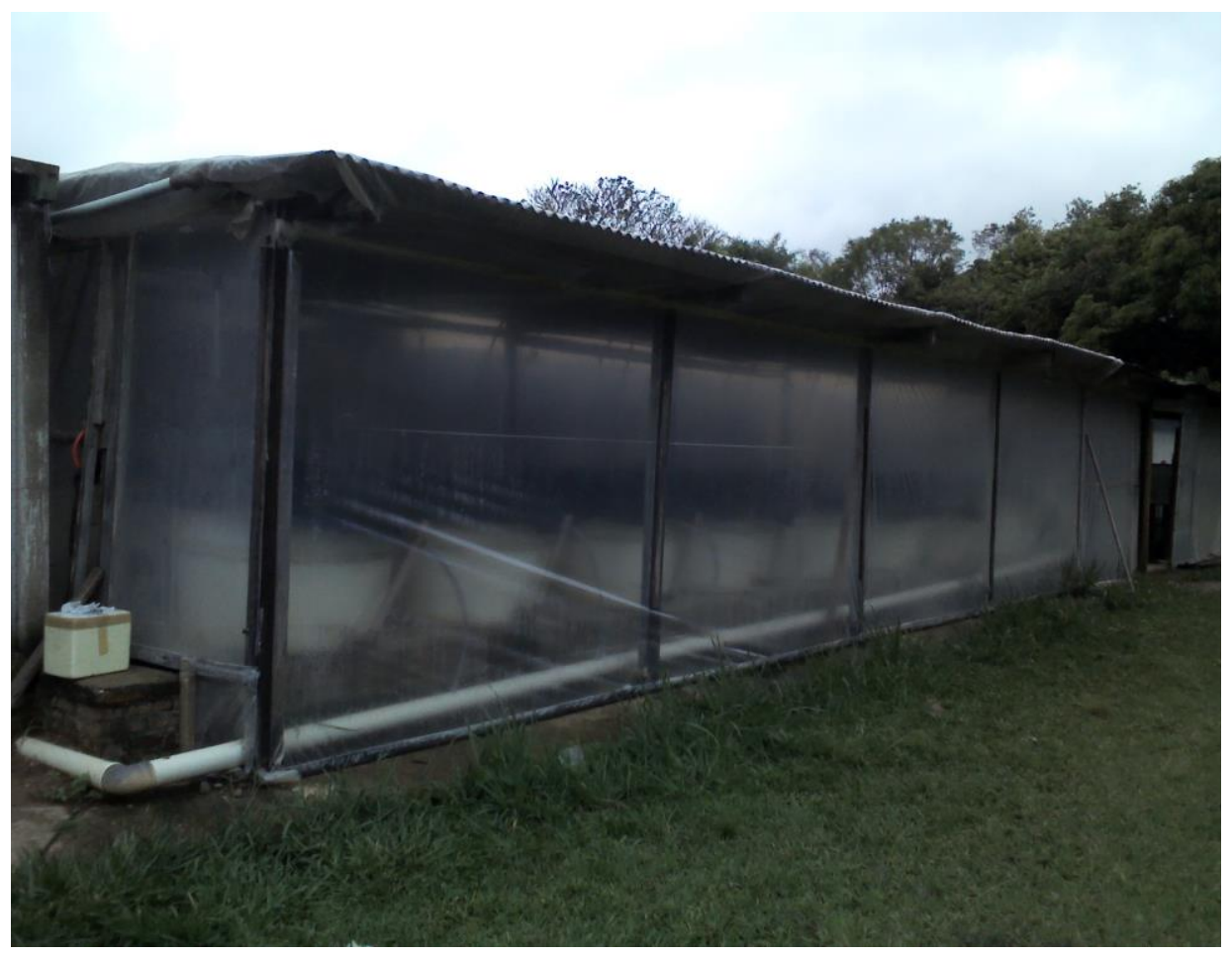

Figura 2 . Local do experimento Núcleo de Tecnologia em Piscicultura e Pecuária da Secretaria de Estado da Agricultura, Abastecimento e Desenvolvimento Rural do Distrito Federal, localizado em Brasília-DF. 


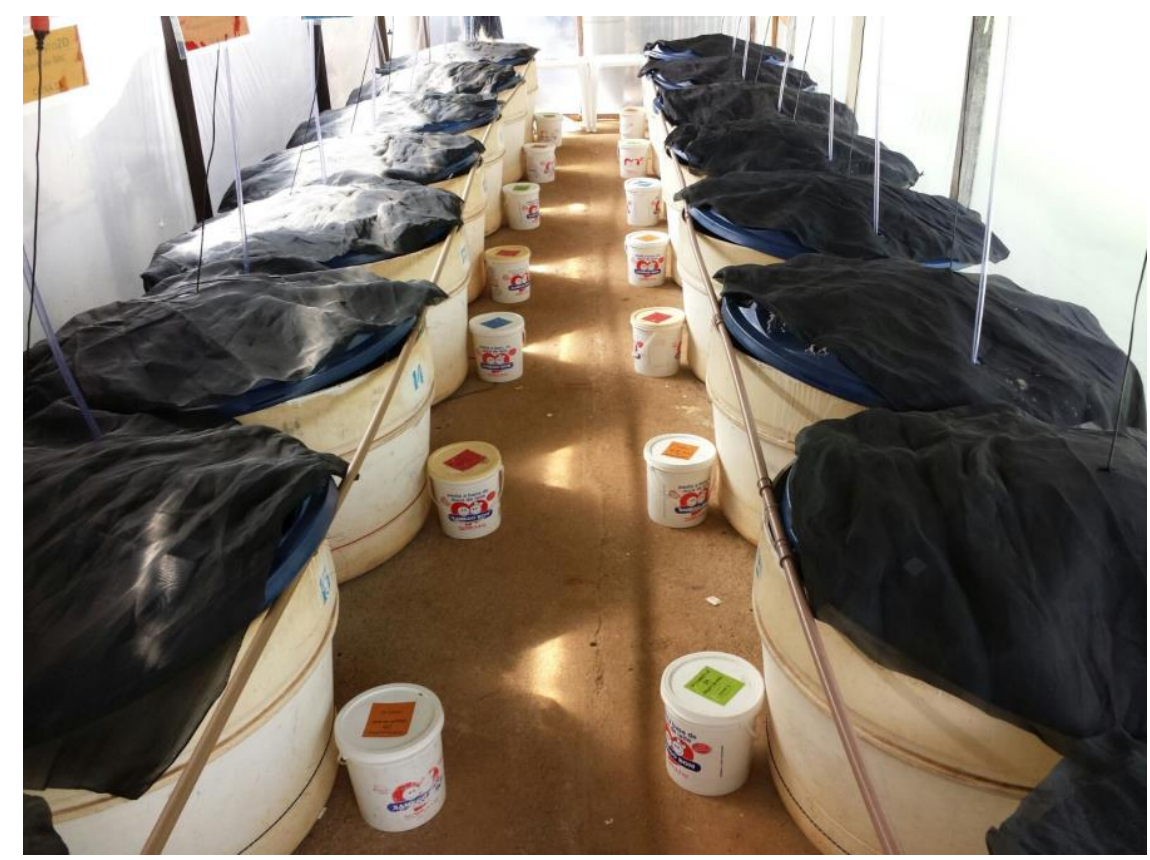

Figura 3. Local do experimento Núcleo de Tecnologia em Piscicultura e Pecuária da Secretaria de Estado da Agricultura, Abastecimento e Desenvolvimento Rural do Distrito Federal, localizado em Brasília-DF.

Foram utilizados 64 peixes, tilápias do Nilo (Oreochromis niloticus) da linhagem GIFT, machos revertidos, com peso médio de 500 gramas, distribuídos aleatoriamente em 16 caixas d'água de amianto, com capacidade de 500 litros, totalizando 4 animais por caixa durante 40 dias. Os animais foram identificados individualmente utilizando-se microchips da marca Allflex ${ }^{\circledR}$. A temperatura do sistema foi mantida à $27^{\circ} \mathrm{C}$ por termostatos individuais em cada caixa.

As rações recebidas pelos peixes foram preparadas na Universidade Federal de Viçosa, extrusada e com diâmetro de 5mm, utilizando a formulação que cumpre com as exigências nutricionais para a espécie, segundo Boscolo (2009), como mostra a tabela 1. 
Tabela 1- Níveis de garantia das rações utilizadas para alimentação dos machos revertidos de de tilápia do Nilo durante o período experimental.

\begin{tabular}{|c|c|}
\hline $\begin{array}{l}\text { Nutrientes }(\%) \\
\text { Nutrients }\end{array}$ & $\begin{array}{c}\text { Fase de } \\
\text { crescimento } \\
\text { Growing } \\
\text { phase }\end{array}$ \\
\hline $\begin{array}{l}\text { Energia digestivel }(\mathrm{kcal} / \mathrm{kg}) \\
\text { Digestible energy }\end{array}$ & 3000,00 \\
\hline $\begin{array}{l}\text { Proteina bruta (minimo) } \\
\text { Crude protein (minimum) }\end{array}$ & 28,00 \\
\hline Gordura (minimo) & 4,00 \\
\hline $\begin{array}{l}\text { Fat (minimum) } \\
\text { Fibra bruta } \\
\text { (minimo-máximo) }\end{array}$ & 12,00 \\
\hline $\begin{array}{l}\text { Crude fiber (minimum- maximum) } \\
\text { Cálcio (minimo) } \\
\text { Calcium (minimum) }\end{array}$ & 1,20 \\
\hline $\begin{array}{l}\text { Fósforo (máximo) } \\
\text { Phosphorus (maximum) }\end{array}$ & 0,90 \\
\hline
\end{tabular}

Antes do período experimental, os peixes foram submetidos a um período de aclimatação de 15 dias. Nesse período os animais foram alocados em 2 tanques de alvenaria revestidos com azulejos com capacidade de 15.000 litros cada e receberam a mesma ração destinada ao grupo controle do experimento, ou seja, sem adição de ractopamina, porém com a mesma formulação básica. Durante o período experimental os peixes foram alimentados diariamente com as rações (duas vezes por dia) ad-libitum, sendo uma vez pela manhã e uma a tarde.

A densidade de peixes manteve-se constante em torno de $10 \mathrm{~kg} / \mathrm{m}^{3}$, havendo um controle do volume de água de cada caixa após as eutanásias. Foram realizados monitoramentos diários, individuais em cada caixa, dos parâmetros físico-químicos da água, como temperatura, $\mathrm{pH}$, oxigênio dissolvido, amônia, nitrito e nitrato por meio de kit digital portátil (ALFAKIT - AT300).

Utilizou-se o sistema de cultivo de recirculação fechada, composto por um sistema de filtro mecânico e biológico, havendo um retorno da água para os tanques de $100 \%$ a cada 2 horas e uma renovação de no máximo $10 \%$ de água por dia.

O delineamento experimental foi inteiramente casualizado, composto por 4 tratamentos com ractopamina incorporada na ração em diferentes concentrações $(0$ ppm de ractopaminha, $10 \mathrm{ppm}$ de ractopamina, $20 \mathrm{ppm}$ de ractopamina e $40 \mathrm{ppm}$ de ractopamina) de acordo com o seguinte:

Os animais foram distribuídos em 16 caixas, totalizando 4 caixas por tratamento (4 repetições). 
Foram realizadas coletas em 2 tempos distintos, sendo: $\mathrm{T}_{1}-20$ dias de tratamento e $\mathrm{T}_{2}$ - 40 dias de tratamento. A cada tempo de coleta, 2 peixes de cada caixa foram escolhidos aleatoriamente para a coleta e anestesiados com eugenol na dosagem de 2,35mg/L. Foram coletados aproximadamente $3 \mathrm{~mL}$ de sangue de cada animal, por meio de punção da veia caudal, utilizando-se seringas descartáveis de $5 \mathrm{~mL}$ com agulhas $25 \times 7$, sendo estes animais posteriormente eutanasiados por secção da artéria branquial. Do volume total de sangue retirado de cada animal, $1 \mathrm{~mL}$ foi acondicionado e homogeneizado em tubos plásticos previamente identificados, contendo $\operatorname{EDTA}(0,1 \mathrm{~mL})$ como anticoagulante para a preservação das amostras destinadas à ensaios hematológicos (Tavares-Dias et al., 2001), 1 mL de sangue foi armazenado em tubos plásticos sem anticoagulante para a obtenção de soro para a dosagem de cortisol e $1 \mathrm{~mL}$ em tubos contendo anticoagulante EDTA $(0,1 \mathrm{~mL})$ e fluoreto de sódio $(0,1 \mathrm{~mL})$ para a determinação da concentração plasmática de lactato.

Após a obtenção, as amostras foram encaminhadas ao Laboratório de Patologia Clínica Veterinária da Universidade de Brasília, para o armazenamento e processamento das análises.

Além das dosagens bioquímicas de cortisol e lactato, foram avaliados parâmetros hematológicos (contagem de eritrócitos, leucócitos, proteínas totais, volume globular, hemoglobina, hematócrito.

O hematócrito (em \%) foi determinado por meio da técnica de micro hematócrito com capilares heparinizados, segundo a técnica de Goldenfarb et al. (1971). A concentração de hemoglobina total $([\mathrm{Hb}]=\mathrm{g} / \mathrm{dL})$ foi determinada a partir da técnica do cianeto hemoglobina, proposta por Collier (1944). Para a contagem de eritrócitos e leucócitos foi empregada a solução de formol citrato, em que a contagem dos leucócitos totais e eritrócitos foi realizada de forma direta em câmara de Neubauer.

Para a determinação plasmática da concentração de lactato, as amostras foram centrifugadas para retirada do plasma, e posteriormente utilizando um kit comercial da marca Kovalent $^{\circledR}$ (MS/ANVISA 80115310042). Para a determinação da concentração de cortisol, foram utilizadas as frações de soro obtidas por centrifugação das amostras sem o uso de anticoagulante, utilizando-se o kit Cortisol - Elisa - Biochem ${ }^{\circledR}$.

A análise dos dados foi realizada utilizando-se o Programa Statistical Analysis System (SAS® v.9.3 Cary, North Carolina), sendo os resultados hematológicos e bioquímicos submetidos à análise de variância com posterior comparação de médias pelo teste de Tukey a 5\% de significância. Para se determinar as correlações entre os resultados hematológicos e 
bioquímicos, foi aplicada a Correlação de Pearson. Em todas as análises realizadas, valores de $\mathrm{p}<0,05$ indicaram significância estatística.

Este experimento foi submetido à avaliação pelo Comitê de Ética no Uso Animal do Instituto de Ciências Biológicas da Universidade de Brasília e aprovado sob protocolo CEUA/UnB (70411/2014). 


\section{3 - RESULTADOS E DISCUSSÃO}

\section{1 - Parâmetros Bioquímicos}

No presente estudo, não houve diferença estatística significativa nas concentrações de cortisol nos diferentes níveis de ractopamina, em nenhum dos tempos de coleta, de acordo com a tabela 2. Corroborando com Marchant-Forde et al. (2003), que trabalhando com outras espécies de animais, avaliaram a concentração de cortisol em suínos na fase de terminação em animais que receberam ração suplementada com ractopamina, e concluíram que não houve diferença deste parâmetro entre os tratamentos.

Os resultados obtidos neste experimento, mesmo que não significativos entre os tratamentos e tempos de coleta, indicam que as concentrações de cortisol apresentaram-se elevadas inclusive no tempo 0 e nos animais controle, indicando um possível estresse gerado talvez pelo manejo ou pela mudança de ambiente. Tais valores quando comparados aos valores de referência descritos por Wedemeyer et al. (1990), que determinam que concentrações basais de cortisol de peixes em repouso devem ser inferiores a $40 \mathrm{ng} / \mathrm{mL}$, o que coincide com valores encontrados por diversos autores (16,43 a 46,32 ng/mL) (Barcellos et al., 1999; Sanches, 2013). Segundo Summers et al., (2005), quando estressados, os peixes podem apresentar um aumento de cerca de 4 vezes nos valores do cortisol.

Os resultados encontrados para concentração de lactato e cortisol estão descritos na Tabela 2. 
Tabela 2 - Médias e desvios padrão das concentrações de lactato e cortisol sanguíneos em tilápias do Nilo (Oreochromis niloticus) suplementadas com diferentes níveis de ractopamina na dieta, Brasília, 2014.

\begin{tabular}{|c|c|c|c|c|c|}
\hline \multirow[t]{2}{*}{ Variável } & $\begin{array}{c}\text { Temp } \\
\text { o } \\
\text { (Dias) }\end{array}$ & & $\begin{array}{l}\text { Tratamento } \\
\text { (ppm) }\end{array}$ & & \\
\hline & & 0 & 10 & 20 & 40 \\
\hline \multirow{3}{*}{$\begin{array}{c}\text { Lactato } \\
(\mathrm{mmol} / \mathrm{L})\end{array}$} & 0 & $4,61 \pm 2,36^{\mathrm{A}}$ & - & - & - \\
\hline & 20 & $4,68 \pm 3,65$ Аа & $3,79 \pm 2,26^{\mathrm{Aa}}$ & $2,76 \pm 1,24^{\mathrm{Ba}}$ & $3,13 \pm 2,41^{\mathrm{Aa}}$ \\
\hline & 40 & $4,54 \pm 2,87 \mathrm{Aa}$ & $2,79 \pm 1,89^{\mathrm{Aa}}$ & $2,96 \pm 1,63^{\mathrm{Ba}}$ & $3,15 \pm 1,36$ Аа \\
\hline \multirow{3}{*}{$\begin{array}{l}\text { Cortisol } \\
\text { (ng/mL) }\end{array}$} & 0 & $109,55 \pm 35,66^{A}$ & - & - & - \\
\hline & 20 & $104,98 \pm 53,07$ Aa & $115,05 \pm 50,05$ Aa & $121,82 \pm 55,8$ Аа & $99,49 \pm 66,01^{\mathrm{Aa}}$ \\
\hline & 40 & $88,01 \pm 47,63$ Аа & $149,27 \pm 78,03$ & $122,85 \pm 52,74$ Aa & $88,12 \pm 46,41$ \\
\hline
\end{tabular}

Médias \pm desvio-padrão seguidas por letras diferentes (maiúsculas em coluna e minúsculas em linha) indicam diferença significativa pelo Teste de Tukey, a $5 \%$ de probabilidade.

Os níveis de lactato apresentaram uma diminuição significativa no tempo de coleta (20 e 40 dias) no grupo suplementado com 20 ppm de ractopamina $(2,76 \pm 1,24$ e 2,96 $\pm 1,63$, respectivamente), quando comparado ao controle e a tempo 0 (zero) (Tabela 2). Tais resultados diferem dos encontrados por Athayde, (2010), ao testar o estresse em suínos alimentados com ractopamina, onde não observaram efeito para esse parâmetro.

Em trabalho realizado por Brandão et al., (2006) o lactato apresentou uma diminuição significativa logo após o transporte quando comparado ao controle decorrentes da intensa natação do cardume no tanque de criação e as disputas territoriais que podem ter havido, sendo a tilápia um peixe de comportamento territorialista.

As concentrações de cortisol e de lactato não apresentaram correlação no estudo do coeficiente da correlação linear de Pearson com nenhuma outra variável analisada neste trabalho.

\section{2 - Parâmetros Hematológicos}

No presente trabalho, os diferentes tratamentos avaliados não influenciaram $(\mathrm{p}<0,05)$ a contagem total de hemácias, o percentual do hematócrito, o teor de hemoglobina, os valores de leucócitos, assim como demonstrado na Tabela 3. Estes resultados são 
semelhantes ao descrito por Barros et al. (2002) e Silva et al. (2012), ao avaliarem parâmetros hematológicos de alevinos de Tilápias do Nilo submetidos a situações de estresse, também não observaram alterações nestes parâmetros. E também corroboram com Bicudo et al., 2012, ao analisar pacus criados em sistema de recirculação, alimentados com ração contendo ractopamina, onde não houveram diferenças significativas no hematócrito, Hemoglobina e hemácias entre os peixes alimentados com e sem o promotor de crescimento.

Tabelas 3 - Médias e desvios padrão das concentrações dos parâmetros hematológicos de tilápias (Oreochromis niloticus) suplementadas com diferentes níveis de ractopamina na dieta, Brasília, 2014.

\begin{tabular}{|c|c|c|c|c|c|}
\hline \multirow[t]{2}{*}{ Variável } & \multirow[t]{2}{*}{$\begin{array}{c}\text { Temp } \\
\mathbf{0}\end{array}$} & \multicolumn{3}{|c|}{$\begin{array}{c}\text { Tratamento } \\
\text { (ppm) }\end{array}$} & \multirow[b]{2}{*}{40} \\
\hline & & 0 & 10 & 20 & \\
\hline \multirow{3}{*}{$\begin{array}{l}\text { Hemoglobin } \\
\text { a (g/dL) }\end{array}$} & 0 & $7,75 \pm 1,02^{\mathrm{A}}$ & - & - & - \\
\hline & 20 & $7,48 \pm 0,16^{\mathrm{aA}}$ & $7,81 \pm 0,79$ aA & $7,37 \pm 0,90^{\mathrm{aA}}$ & $7,35 \pm 0,68{ }^{\mathrm{aA}}$ \\
\hline & 40 & $7,06 \pm 0,71^{\mathrm{aA}}$ & $6,78 \pm 1,57^{\mathrm{aA}}$ & $6,73 \pm 1,03^{\mathrm{aA}}$ & $6,76 \pm 1,06^{\mathrm{aA}}$ \\
\hline \multirow{3}{*}{$\begin{array}{l}\text { Hemácias } \\
\left(10^{6} / \mu L^{-1}\right)\end{array}$} & 0 & $2,58 \pm 0,33^{\mathrm{A}}$ & - & - & - \\
\hline & 20 & $2,64 \pm 1,49^{\mathrm{aA}}$ & $2,69 \pm 0,34^{\mathrm{aA}}$ & $2,64 \pm 0,42^{\mathrm{aA}}$ & $2,73 \pm 0,45^{\mathrm{aA}}$ \\
\hline & 40 & $2,85 \pm 0,57^{\mathrm{aA}}$ & $2,89 \pm 0,31^{\mathrm{aA}}$ & $2,76 \pm 0,56^{\mathrm{aA}}$ & $2,81 \pm 0,41^{\mathrm{aA}}$ \\
\hline \multirow{3}{*}{ HTO (\%) } & 0 & $33,12 \pm 3,78^{\mathrm{A}}$ & - & - & - \\
\hline & 20 & $30,04 \pm 7,04^{\mathrm{aA}}$ & $31,85 \pm 2,99^{\mathrm{aA}}$ & $36,28 \pm 5,70^{\mathrm{aA}}$ & $32,50 \pm 7,36^{\mathrm{aA}}$ \\
\hline & 40 & $31,38 \pm 10,86^{\mathrm{aA}}$ & $32,20 \pm 7,78^{\text {aA }}$ & $37,05 \pm 8,23^{\mathrm{aA}}$ & $36,75 \pm 4,73^{\mathrm{aA}}$ \\
\hline \multirow{3}{*}{$\begin{array}{c}\text { Leucócitos } \\
(/ \mu \mathrm{L})\end{array}$} & 0 & $48857 \pm 21100^{\mathrm{A}}$ & - & - & - \\
\hline & 20 & $46600 \pm 14537^{\mathrm{aA}}$ & $64428 \pm 21048^{\mathrm{aA}}$ & $44857 \pm 20330^{\mathrm{aA}}$ & $57750 \pm 39212^{\mathrm{aA}}$ \\
\hline & 40 & $59312 \pm 17444^{\mathrm{aA}}$ & $59900 \pm 11315^{\mathrm{aA}}$ & $54562 \pm 20157^{\mathrm{aA}}$ & $60000 \pm 23800^{\mathrm{aA}}$ \\
\hline
\end{tabular}

Médias \pm desvio-padrão seguidas por letras diferentes (maiúsculas em coluna e minúsculas em linha) indicam diferença significativa pelo Teste de Tukey, a 5\% de probabilidade.

Apesar de não terem apresentado diferenças significativos $(\mathrm{p}<0,05)$ entre os tratamentos e tempos, os valores de hemácias e o hematócrito apresentam-se ligeiramente elevados em relação aos valores de referência $(2,15 \pm 0,12$ e 27,85 $\pm 1,65$, respectivamente) descritos por Ueda, (1997), diferindo de Brandão et al., 2006, que ao testarem a resposta ao estresse de Pirarucus submetidos a práticas de rotina em piscicultura.

De acordo com McDonald e Milligan, (1997), a diminuição de oxigênio no ambiente estimula a eritropoiese, aumentando o Hematócrito e as hemácias em peixes de água 
doce. Isso ocorre devido à liberação de catecolaminas, que causam mobilização das hemácias do baço aumentando sua quantidade no sangue e consequentemente, aumentando o HTO (Mcdonald \& Milligan, 1992). O aumento de HTO também pode representar alterações eletrolíticas e influxo de água na célula (Mcdonald \& Milligan, 1997).

De acordo com Tavares \& Moraes (2004) o estresse leva ainda à ação dos glicocorticoides no organismo dos peixes, cujos níveis de cortisol no sangue são elevados e com isso ocorrem as modificações fisiometabólicas, observadas por meio do aumento do número de eritrócitos.

Possíveis hipóteses quando a não ocorrência de estresse, segundo Mills; Spurlock; Smith, (2003) a utilização contínua de Ractopamina torna o receptor inativo e desacopla o complexo receptor-Gs-adenilato ciclase. O efetor não acoplado migra para o espaço intracitoplasmático, levando à diminuição de receptores disponíveis na membrana. Essa redução na quantidade de receptores é denominada dessensibilização, causando a diminuição da resposta à estimulação betaadrenérgica da RAC. Da mesma forma, no espaço intracitoplasmático, o receptor betaadrenérgico pode ser consumido, conhecido como sequestro, o que acarreta a diminuição de receptores celulares. Esta variação no número de receptores por unidade de sarcolema é denominada "down-regulation".

De acordo com a análise do coeficiente da correlação linear de Pearson não foram encontradas correlações significativas entre as médias das concentrações de hemácias, hemoglobina, leucócitos e proteínas totais com nenhuma das variáveis analisadas. 


\section{4 - CONCLUSÕES}

Os resultados obtidos pelos indicadores hematológicos e bioquímicos neste trabalho não apontaram para um estresse fisiológico produzido pela ingestão de ractopamina nas concentrações de 10, 20 e 40 ppm pelos animais, entretanto, mais estudos acerca do tema devem ser realizados, para que o uso do aditivo seja recomendado de forma segura, quanto ao bem-estar dos peixes. 


\section{5 - REFERÊNCIAS BIBLIOGRÁFICAS}

ATHAYDE N. B. Desempenho, qualidade de carne e estresse de suínos suplementados com ractopamina. Dissertação de mestrado, Universidade Estadual Paulista, Botucatu, São Paulo, Brasil 2010.

BARCELLOS, L. J. G.; NICOLAIEWSKY, S.; SOUZA, S. M. G.; LULHIER F. Plasmatic levels of cortisol in the response to acute stress in Nile tilapia, Oreochromis niloticus (L.), previously exposed to chronic stress. Aquaculture Research. v.30, p.437-444, 1999.

BARROS M. M.; PEZZATO L. E.; KLEEMANN G. K.; HISANO H.; ROSA G. J. M. Níveis de vitamina $\mathrm{C}$ e ferro para tilápia do Nilo (Oreochromis niloticus). Revista Brasileira de Zootecnia. 31:2149-2156, 2002.

BICUDO, A. J. A.; SADO, R. Y.; CYRINO, J. E. P. Growth, body composition and hematology of juvenile pacu (Piaractus mesopotamicus) fed increasing levels of ractopamine. Arquivo Brasileiro de Medicina Veterinária e Zootecnia, v. 64, n. 5, p. 1335$1342,2012$.

BOSCOLO, W. R.; HAYASHI, C. M.; SOARES, W. M.; FURUYA E F.; MEURER, C. Desempenho e Características de Carcaça de Machos Revertidos de Tilápias do Nilo (Oreochromis niloticus), Linhagens Tailandesa e Comum, nas Fases Inicial e de Crescimento. Revista Brasileira de Zootecnia v. 30, p. 1391-1396, 2009.

BRANDÃO, F. R.; DE CARVALHO GOMES, L.; CHAGAS, E. C. Respostas de estresse em pirarucu (Arapaima gigas) durante práticas de rotina em piscicultura. Acta Amazonica, v. 36, n. 3, p. 349, 2006.

COLLIER, H. B. The standardization of blood haemoglobin determinations. Canadian Medical Association Journal, Ottawa, v. 50, p.550-552, 1944.

GOLDENFARB, P. B.; BOWYER, F. P.; HALL, E.; BROSIOUS, E. Reproducibility in the hematology laboratory: the microhematocrit determination. American Journal of Clinical Pathology, New York, v. 56, p. 35-39, 1971.

MARCHANT-FORDE, J. N.; LAY, D. C. JR.; PAJOR, E. A. The effects of ractopamine on the behavior and physiology of finishing pigs. Journal of Animal Science, v.81, p. 416-422, 2003. 
MCDONALD, D.G.; MILligAN, C.L. Chemical properties of the blood. In: Fish Physiology (Hoar, W.S.; Randall, d.j.; Farrel, A.P., ed) v. XIIB, San Diego: Academic Press, 1992, p.55-134.

MCDONALD, G.; MILLIGAN, L. Ionic, osmotic and acid-base regulation in stress. In: IWANA, G.K. et al. (Ed.). Fish stress and health in aquaculture. New York: Cambridge University Press, 1997. cap. 5, p. 119-144.

MILLS, S. E.; SPURLOCK, M. E.; SMITH, D. J. Beta-adrenergic receptor subtypes that mediate ractopamine stimulation of lipolysis. Journal of Animal Science, Champaign, v. 81, n. 3, p. 662-668, 2003.

SANCHES, F. H. C. Resposta de estresse à substância de alarme na tilápia-do-nilo. 2013. 28f. Dissertação (Mestrado em Ciências Biológicas - Zoologia) - Instituto de Biociências de Botucatu, Universidade Estadual Paulista. 2013.

SILVA, R. D.; ROCHA L. O.; FONTES D. A.; VIERA D.; FIORAVANTI M. C. Parâmetros hematológicos e bioquímicos da tilápia-do-Nilo (Oreochromis niloticus L.) sob estresse por exposição ao ar. Pesqui. Vet. bras, v. 32, n. supl. 1, p. 99-107, 2012.

SUMMERS, C.H.; WINBERG, S. Interactions between the neural regulation of stress and agression. The Journal of Experimental Biology, v. 209, p.4581-4589, 2006.

TAVARES-DIAS, M.; MORAES, F.R.; MARTINS, M.L.; KRONKA, S.N. Fauna parasitária de peixes oriundos de pesque-pagues do município de Franca, São Paulo, Brasil. II. Metazoários. Revista Brasileira de Zoologia, 18: 81-95. 2001.

UEDA, I. K.; EGAMI, M. I.; SASSO, W. S.; MATUSHIMA, E. R. 1997. Estudo hematológico do sangue periférico de O. nilocitus (Linneus, 1758). Braz. J. Vet. Res. Anim. Sci., 34:270-275.

WEDEMEYER GA, BARTON B, MC LEAY D. Stress and acclimation. In: Schereck C, Moyle P. (Ed.). Methods for fish biology. Bethesda, MD: American Fisheries Society, 1990. p. 451-489. 